\title{
Hal Foster - O retorno do real: a vanguarda no final do século $X X$
}

Tradução de Célia Euvaldo. São Paulo: Cosac Naify, 2014

João Carlos Felix de Lima ${ }^{1}$

Premido por inúmeras visões concorrentes da coisa literária, e, neste início de milênio, das conexões entre as artes, o interessado em teoria poderá enredar-se em inextricáveis nós de discórdia e paixão, se, por um ato de honestidade, resolver conhecer as vertentes interpretativas erigidas nos últimos 50 anos. Poderá sair com inúmeras fraturas e ainda bastante confuso. Por isso, a esses interessados nos estudos e nas teorias pósmodernos, bem como em suas concorrentes materialistas, a tradução do livro de Hal Foster aparece como um antídoto eficiente porque consegue amalgamar inúmeras vertentes interpretativas, sem se perder em dogmas que menos interpretam a arte e (por isso) a literatura atual.

Nesse sentido, o livro traça inúmeras conquistas teóricas e permeia todos os aspectos que subsumem o termo "pós-moderno". No entanto, para quem acha que isso significa uma história do termo, logo nos pórticos das páginas iniciais se entende que não. Trata-se de uma tentativa de apreensão e de compreensão do estado atual da arte no mundo das performances, das heranças sentidas a partir de Duchamp, da entrada de outros materiais na composição dos objetos artísticos e da forte vigência do mercado, como demandas a serem pensadas nos modelos de arte hoje. Para entrar nessa discussão, Foster precisou fazer todo um ajuste em relação às tarifas cobradas pelo modernismo em termos de herança, manietada pelas perspectivas vanguardistas - já que ambos não se confundem ou, pelo menos, não são iguais.

Foster está desde o início de sua formação ligado às questões intelectuais contemporâneas. Em seus trabalhos mais recentes, posicionou-se quanto às demandas e urgências do presente na arte. Assim, seus livros ora trafegam pelos domínios da psicanálise em comunhão com a arte, como em Prosthetic gods, de 2004, e pelas relações entre a modernidade e a arquitetura, como em The art and architecture complex, de 2013. Seu Arte, recepção e espetáculo, política cultural foi publicado por aqui

${ }^{1}$ Doutor em literatura pela Universidade de Brasília (UnB), Brasília, DF, Brasil. E-mail: jchilst@yahoo.com.br 
em 1996. E, inicialmente, como editor, The anti-aesthetic: essays on postmodern culture, de 1983, Foster fez uma pergunta que nos diz de perto: "Pós-modernismo: ele existe e, se sim, o que significa?" (Foster, 1983, p. ix). Trata-se de um volume importante ainda por conter ensaios críticos contrários, inclusive, a algum direcionamento pós-modernista, como os de Fredric Jameson e Jürgen Habermas.

Foster entende que o modernismo formal, ligado a um eixo "diacrônico ou vertical", se pronunciaria contrário a "um modernismo vanguardista" ("sincrônico ou horizontal"), operador, segundo suas próprias diretrizes, de uma "quebra com o passado" (Foster, 2014, p. 8). Por isso, Foster assinala o quanto o modernismo deve à neovanguarda, já que dispensou a esses dois eixos uma simetria aguçada e em "coordenação crítica". A partir dessa partilha forçada entre os termos, lida através de uma virada etnográfica, na qual os atores de outras cenas apareceriam por meio, claro, de trabalhos muito específicos, é que o "debate torna-se pronunciado" (Foster, 2014, p. 9). Foster estuda esse movimento no final de seu livro e o anuncia como uma (boa) promessa para o futuro.

Quanto ao valor (normativo, estético, formal etc.) da arte contemporânea, Foster pondera o caráter "provisório" das invenções formais. Declaração muito diferente da indicativa de qualquer "vale tudo estético" que parece acompanhar parte da produção crítica atual, a ponto de contaminar, por assim dizer, todo o juízo que se diz da arte hoje. "Existe sempre uma invenção formal a ser redesdobrada, um capital cultural a ser reinvestido" (Foster, 2014, p. 9). Esse caráter provisório, como dissemos, é parte deste tempo de mudanças, em que os eixos de transformações históricas se desdobram uns sobre os outros, no rio convalescente da urgência do extremamente novo e de sua mímesis representativa.

Foster é um crítico que se alia, de um lado, a algumas questões próprias aos pós-modernistas, em geral, como leitor que é de Derrida, e, por outro, não deixa de pensar a arte dentro de uma perspectiva pós-frankfurtiana, isto é, para ele, o passado, como narrativa, precisa ser reencontrado, no que "depende [...] de nossas posições no presente" (Foster, 2014, p. 10). O engajamento, se existe, está no agora. Sua aposta fundamental é a de que devemos com toda a urgência retomar o debate crítico, interrompido com o que ele denomina "golpe neoconservador dos anos 1980", quando, claro está, os Estados Unidos 
seguiam o reaganomic pacto que teria desarticulado a arte e desmobilizado a crítica. Diante disso, a vigência de Walter Benjamin oxigena as demandas críticas do autor.

Foster investe contra algumas percepções de Peter Bürger a respeito da vanguarda histórica, vista por Bürger como continuum de "origem absoluta". Foster vê essa "autopresença" como "suspeita". Bürger, como se sabe, teve sua formação ligada a Adorno, por isso, sua obra Teoria da vanguarda, postulada sobre a teoria crítica adorniana, mas não só, abre espaço para uma discussão que o próprio Adorno não teve tempo senão de esboçar: o espectro das vanguardas. Para Foster, Bürger de fato se erige como ponto de inflexão, mas não deixa de ser criticável por essa miopia. Não é surpresa que o livro de Bürger tenha causado polêmica, sobretudo na Alemanha. Em parte porque, para ele, tanto Duchamp quanto Picasso nascem "prontos", isto é, como se tivessem surgido cada qual como são vistos hoje. O passado não poderia ser mais mal administrado, na visão de Foster:

Duchamp apareceu como "Duchamp"? É claro que não [...] Le Demoiselles d'Avignon de Picasso surgiu como o momento crucial da pintura que agora se lhe atribui? Obviamente não [...] Esse ponto cego em Bürger no tocante às diferenças temporais em relação ao significado de uma obra é irônico, pois ele costuma ser elogiado por sua atenção à historicidade das categorias estéticas (2014, p. 27, grifos do original).

Foster ainda indica que o projeto de Bürger tomaria como pressuposto a retórica da tradição e da ruptura (românticas na origem e conceito), tão queridas de Octavio Paz, mencionando que Bürger acabou esquecendo-se da "dimensão mimética, por meio da qual a vanguarda mimetiza o mundo degradado da modernidade capitalista não para aderir a ele, mas para dele escarnecer" (Foster, 2014, p. 35). A arte pósmoderna foi atacada, diz Foster, não pelo performativo, que poderia indicar outro rumo à sua "percepção", que estaria aliada à sua "linguagem", às suas "instituições e estruturas de significado", bem como às suas "expectativa e recepção", dimensões que definem, por assim dizer, ambiguidades artísticas atuais.

Vem dessas considerações a melhor definição que encontro no livro de Ready made, localizada naquilo que Walter Benjamin enunciou como predicado da extrema autonomia que o objeto artístico singular suporta e de sua presença, já que ele estaria em qualquer lugar, mesmo onde 
nunca poderia estar (Benjamin, 1994, p. 168 e ss.). O Ready made "articula[ria] as condições enunciadoras da obra de arte de fora, como objeto extrínseco. Mas o efeito é revelar os limites convencionais da arte num tempo e lugar específicos" (Foster, 2014, p. 37, grifos do original). Essa fragmentariedade e ao mesmo tempo precariedade do objeto artístico estariam relacionados com a subjetividade contemporânea, nunca estabelecida de uma vez por todas, vide Freud/Lacan, e lida como sucedâneo de "antecipações", bem como de "reconstruções de eventos traumáticos", contemplados na maneira como a vanguarda histórica e a neovanguarda constituem-se em "complexa alternância de futuros antecipados e passados reconstituídos" (Foster, 2014, p. 46).

A temporalidade da vanguarda, segundo isso, mobiliza tempos paradoxais: passado e futuro se alternam. Tanto a crítica (especialmente a pós-estruturalista) quanto a arte pós-modernista desenvolveriam questões atreladas a essa temporalidade, difícil de entender, mas presente nas questões que se pronunciam como específicas, sempre, a posteriori: "questões de repetição, diferença e adiamento; de causalidade, temporalidade e narratividade" (Foster, 2014, p. 48). Uma espécie de "eterno retorno" condicionado apenas pela objectualidade e fenomenalidade do objeto artístico. Por que essas questões, que já atravessavam transversalmente a obra de Edmund Husserl e de Ferdinand de Saussure, não foram discutidas no tempo de origem do modernismo - basta lembrar que ambas - estratégia filosófica e teoria linguística - nasceram ali? Edmund Husserl permaneceu proibido de ensinar publicamente por sua ascendência judaica, e a obra de Saussure, embora prolífica, permaneceu quase toda manuscrita; seu Cours não seria sequer publicado por ele, ademais, ele estaria comprometido por dificuldades de interpretação, dada a sua difícil "metalinguagem", bem como sua quase surpreendente "formalização fraca" (Lopes, 1997, p. 46-47).

A partir dos anos 1960, graças a esforços de intelectuais como Barthes, Derrida, Lévi-Strauss e Ricoeur, os estudos nessa área aprofundaram-se notavelmente e contaminaram todo o ramerrão dos estudos literários e antropológicos. No entanto, havia ainda sérias restrições à fenomenologia, já que sobre si mesma pairava uma penumbra de sabor residual, identificáveis na consciência idealista e na defesa do humanismo, antes criticado pelo estruturalismo e minado por ele desde dentro. Essas questões teóricas são importantes no 
desenvolvimento do livro como um todo, tomam, porém, pouco espaço frente às análises artísticas que se impõem no corpus do trabalho.

Por isso, é interessante acompanhar a discussão que desenvolve Foster sobre a arte minimalista por nos deixar pistas bastante coerentes a respeito da arte contemporânea. Para ele, há uma pregnância de objetos artísticos que não se concentram na tela, que pervagaria a escultura mais notavelmente; tal a arte minimalista, que seria uma "contração da escultura até se tornar o puro objeto modernista e, ao mesmo tempo, uma expansão da escultura para além do reconhecimento" (Foster, 2014, p. 61). A escultura minimalista, ela sim, prepara o plano de recepção da arte pósmodernista. Ao mesmo tempo que isso nos instiga quanto a esse saldo, Foster identifica no artista plástico Michael Fried uma ainda incipiente ideia de que a arte pós-modernista esvazia o conteúdo da arte moderna, e cita uma frase bastante eloquente dessa defesa, não dele, aliás, mas de Greenberg, de que uma tela em seu estado puro é uma tela, por isso mesmo, ela não pode estar resolvida por si mesma.

Outra vez ele retorna ao que disse Lyotard, em sua aposta na derrocada das grandes narrativas, por tabela, das grandes totalidades, como "Deus, natureza prístina, formas platônicas, gênio artístico [que] começaram a desmoronar" (Foster, 2014, p. 75). Essa derrocada está atrelada ao surgimento da serialidade, da pop arte e do minimalismo. A repetição seria ainda "o paradigma da representação", a "lógica da diferença e repetição é uma $2^{a}$ natureza para nós" (Foster, 2014, p. 76). Próximo de uma ideia que já se vinha notando em críticos os mais diversos, a de uma arte que se pronuncia como "texto", indicativa dessa ampliação nos campos da cultura, cuja natureza é "extremamente textual". Os modelos que sustentariam forças de vetores opostos, como "alta cultura versus cultura de massa", "arte autônoma versus arte utilitária" foram sendo combatidos justamente pelo novo modelo de arte como texto, conquista, segundo Foster, da arte pós-modernista e da crítica pós-estruturalista, cuja batalha ainda prossegue. Na década de 1960, isso significava interferir na solidez de categorias e gêneros estéticos estáveis e dados como certos; seriam assim a escultura, a pintura, a literatura etc.

Como, porém, pensar a dinâmica econômica que segue movediça nas condições de existência dessa arte pós-1960? Em História e consciência de classe, Lukács propõe três tipos de reificações, que são, na verdade, etapas da consolidação do capital internacional, isto é, uma 
primeira que seria a de reificação e fragmentação, contaminante do objeto concebido em si mesmo; ainda, o consumo em série, que atingiria agora o signo. Lukács acaba se envolvendo, segundo essa perspectiva, em uma redução do forte movimento de consciência que a subjetividade investe na obra de arte. Por isso, Foster propõe que a arte é antes atravessada pelas "contradições" próprias a ela mesma e à teoria. Como se disse anteriormente, não faz sentido indicar na arte contemporânea qualquer aspecto que se ressinta da velha tradição da mímesis. Estamos naquilo que Foster chama ausência de centro e de presença. Duchamp já havia assinalado a "instabilidade do signo" (Foster, 2014, p. 89), como seria possível assumir qualquer estabilidade agora? O mesmo Lukács se prontificou a denunciar nas formas modernistas réplicas à reificação do capital. Faltou-lhe lucidez para entender seu momento e tempo como provocadores de outras rupturas, imprevistas por sua teoria.

Não há símbolo, há alegoria. Essa constatação representa os momentos da arte em que a aparência é conectada a um tipo de realidade:

a arte pós-modernista é alegórica não só por sua ênfase nos espaços em ruínas (como nas instalações efêmeras) e nas imagens fragmentárias (como em apropriações da história da arte e dos meios de comunicação de massa), mas, acima de tudo, por seu impulso para subverter as normas estilísticas, para redefinir as categorias conceituais, para desafiar o ideal modernista de totalidade simbólica (Foster, 2014, p. 92).

Qual o valor da obra de arte pós-Duchamp? Ela apresenta um valor estético, mas, ao mesmo tempo, subtrai-se em um valor de uso. Arte e consumo tornam-se um só. Esse trânsito mobilizou autores os mais diversos na perspectiva de uma arte estritamente voltada para o mercado. Fredric Jameson, crítico contumaz desse ideário, sugere uma oportuna vigência de cultura de massas $e$ arte, mesmo que os artistas mais novos nada citem: eles, antes, se introjetaram de tal maneira que são irreconhecíveis, advindo daí uma impossível conciliação de análise que seja fruto de teorias anteriores a essa receita. "O que se costumava ser estigmatizado como cultura comercial ou de massa passa agora a ser percebido no recinto de um domínio cultural novo e ampliado" (Jameson, 2004, p. 41). Outro problema, identificado ainda por Foster, é que a assinatura do "autor" da obra vale mais que a própria obra. Hoje, consomem-se Koons, Hirst, não a obra per se (Foster, 2014, p. 109). Nessa empreitada algo burlesca, Koons "cumpriu o que Benjamin predisse 
muito tempo antes: a necessidade cultual de compensar a aura perdida da arte com o 'clarão putrefato' da mercadoria e do público" (Foster, 2014, p. 111). A arte é veículo de prestígio e de desejo. Trata-se, também, da razão cínica, que Sloterdjik descreve. Como entende esse filósofo a razão desta era? Por meio de uma identificação tácita entre instinto e proteção, de uma negociata das contradições que lhe são dirigidas pelo mundo. É dentro da arte que se compõe um quadro cínico muito singular e específico, demanda dos tempos urgentes de hoje. A razão cínica viria também como antídoto a certo exagero da razão desconstrucionista, contra "as previsíveis pretensões à verdade da crítica da ideologia" (Foster, 2014, p. 116).

A arte pós-moderna é vivida como uma espécie de trauma, fato evidenciado pelo esquema do real que ele transmite. A ordem simbólica, nesse sentido, está inscrita numa economia psíquica, via acontecimento traumático. Os objetos artísticos são contaminados pelo olhar, mas são, por ele também, compungidos no tráfego de sentido que se coloca como condição de existência. "Eu estou no quadro" é o mote que desata o narcisismo contemporâneo. Toda arte é uma “domesticação" do olhar. Daí a partilha que o hiper-realismo traz para o debate contemporâneo. Seria um subterfúgio contra o real, desrealizando-o, mas, este o problema, ele "antes exalta que questiona" (Foster, 2014, p. 138) o presente em que se insere.

Essa maneira de interpretar os dados da arte, condicionada por uma economia que, no fim das contas, é economia em vários sentidos, inclusive a econômica, alcança pelo menos duas dimensões na obra de dois pensadores atuais muito lidos no mundo inteiro: Barthes e Baudrillard. Para o primeiro, trata-se de uma ruptura, daí a noção de "simulacro". Para o segundo, porém, mercado e arte haviam definitivamente se juntado em uma "política do signo-mercadoria" (Foster, 2014, p. 124).

O ponto de inflexão dessa arte pós-moderna estaria associado à perspectiva do etnólogo, desenvolvida por Foster no fim do livro. Dela adviria a crítica à instituição capitalista; se voltaria para a alteridade e para a cultura; presentificaria predicados contextuais, conciliaria posições interdisciplinares e seria autocrítica. Daí que "essa 'ideologia do texto', essa recodificação da prática como discurso, persiste na nova antropologia e na arte quasi-antropológica, como ocorre nos estudos culturais e no novo historicismo, a despeito das ambições contextualistas 
que também impulsionam esses métodos" (Foster, 2014, p. 170). Tais são os paradigmas fortes com que se depara o leitor de Foster.

\section{Referências}

BENJAMIN, Walter (1994). A obra de arte na era de sua reprodutibilidade técnica. In: BENJAMIN, Walter. Obras escolhidas. Tradução de Sérgio Paulo Rouanet. 7. ed. São Paulo: Brasiliense. v. 1.

FOSTER, Hal (Ed.) (1983). The anti-aesthetic: essays on postmodern culture. Seattle: Bay Press.

JAMESON, Fredric (2004). Espaço e imagem: teorias do pós-moderno e outros ensaios. Tradução de Ana Lúcia de Almeida Gazzola. Rio de Janeiro: Editora UFRJ.

LOPES, Edward (1997). A identidade e a diferença: raízes históricas das teorias estruturais da narrativa. São Paulo: Editora USP. 